\title{
Правовая и законная борьба против COVID-19: германское прецедентное право, связанное с комендантским часом
}

\section{Себастьян фон Мюнхов}

Европейский чентр исследований в области безопасности им. Джорджа К. Маршалла, https://www.marshallcenter.org

Резюме: Много было написано о попытках Китая и России использовать пандемию, чтобы изменить международный порядок в пользу авторитарных режимов. Когда COVID-19 накрыл Европу и США в начале марта 2020 года, были развернуты дипломатические инициативы, поэтапные операции по оказанию помощи и пропаганда с использованием троллей. Эти действия должны были показать, что централизованные, нелиберальные модели управления лучше подготовлены к управлению кризисом. Напротив, трансатлантический мир борется с вирусом с помощью мер, принимаемых в соответствии со стандартами верховенства закона. В предыдущей статье автор высказал мнение, что разница зависит от доступа к средствам правовой защиты. Весной и в начале лета 2020 года суды Германии вынесли решения по ряду дел, по которым истцы оспаривают правила изоляции. Некоторые из этих решений заслуживают более внимательного рассмотрения, поскольку они углубляют понимание того, как вместо ограничений оцениваются конституционные требования. Поэтому статья начинается с краткого обзора судебной системы Германии по оспариванию исполнительных решений. Затем мы обсудим некоторые интересные судебные постановления. В конце статьи делается попытка оценить какое прецедентное право в отношении COVID-19 возникает в Германии. Могут ли суды сбалансировать основные конституционные принципы, необходимость поддерживать работающий сектор здравоохранения, соблюдение ряда основных прав и подготовить осторожное экономическое восстановление?

Ключевые слова: COVID-19, управление, изоляция, гражданские права, верховенство закона 


\section{Введение}

После начала пандемии COVID-19 много было написано о попытках Китая и России использовать кризис для изменения международного порядка в пользу авторитарных режимов. Когда коронавирус накрыл Европу и США в начале марта 2020 года, были развернуты дипломатические инициативы, организованные операции по оказанию помощи и пропаганда с использованием троллей. Намерение было, и остается, воздействовать на западные общества, терпящие бедствие. Эти действия должны показать, что централизованные, нелиберальные модели управления лучше подготовлены к управлению кризисом. При этом подходе игнорируется вопрос о происхождении вируса, спорная прозрачность при обмене важной информации с остальным миром и упущенные возможности задержать распространение COVID-19 на ранней стадии. Также упускается из виду, что либеральные демократии должны придерживаться верховенства закона при применении инструментов для предотвращения дальнейших инфекций. В работе издания "Security Insights», опубликованной на веб-сайте Центра Джорджа Маршалла в апреле 2020 года, я высказал мнение, что единственными законными мерами против вируса являются меры, принимаемые в соответствии со стандартами верховенства закона. ${ }^{1}$

\section{Вирус и конституционность изоляции}

В работе «Security Insights» рассматривается вопрос о том, как одна из 16 федеральных земель Германии, Бавария, ввела регламентацию введения комендантского часа и какие конституционные пороги необходимо было учитывать при ограничении основных прав. Случай Баварии был выбран потому, что это провинция, в которой было наибольшее число инфицированных и умерших сотрудников, и поэтому Бавария ввела самые жесткие ограничения по сравнению с такими провинциями, как Гамбург, Саксония, Берлин или Рейнланд-Палатин. Я объяснил, что в Германии осуществление общественного здравоохранения подпадает под юрисдикцию земель 16 немецких провинций; таким образом, вирусом COVID-19 занимается 16 министерств здравоохранения, 16 парламентов и 16 правоохранительных органов. Эта особенность имеет значение для внутренних немецких дискуссий о том, как избегать или продвигать лоскутное одеяло из специально созданных ограничений по всей Германии. ${ }^{2}$ Однако, федеральное правительство служит координационным форумом.

1 Sebastian von Münchow, "COVID-19: How to Implement a Lockdown in a Democratic Context," Strategic Insights 57 (Garmisch-Partenkirchen, Germany: George C. Marshall European Center for Security Studies, 2020), https://www.marshallcenter.org/ sites/default/files/files/2020-06/Security\%20Insights\%2057.pdf.

2 Смотри также: Constanze Stelzenmüller and Sam Denney, "COVID-19 Is a Severe Test for Germany 's Postwar Constitution," Lawfare, April 16, 2020, https://www.lawfare blog.com/covid-19-severe-test-germanys-postwar-constitution. 
По вопросу о конституционной законности я высказал мнение, что правительство Свободного государства Бавария принимало решения, которые затрагивали основные права человека и гражданские права его жителей. Я также утверждал, что регламентация комендантского часа тщательно балансировала трилемму Германии и Баварии: сохранить функционирующий сектор здравоохранения, позволить ряду основных прав остаться нетронутыми и подготовиться к ощутимому экономическому восстановлению. Я утверждал, что баварское правительство разработало правила, удовлетворяющие основным требованиям. Постановление о комендантском часе прямо ссылается на баварские и федеральные законы об обеспечении здоровья населения. Для ясности я отметил, что в Мюнхене тщательно сформулированы деятельности, которые следует запретить, и указаны условия, допускающие исключения. Администрация подчеркнула временное состояние этих ограничений. Она выиграла время, чтобы отрегулировать ограничения и экипировать медицинские учреждения.

Доступ к судебной системе оставался открытым, так что граждане и юридические лица могли оспаривать в суде положения указов и исполнительные акты. Этот доступ к правовой системе, как я утверждал, в качестве основы верховенства закона показал, что демократия продолжала функционировать во время пандемии. ${ }^{3}$ Когда я писал свой первый доклад по этой теме, я уже намекнул, что судебная система может столкнуться с волной исков со стороны частных лиц и компаний, которые будут оспаривать ограничения, связанные с комендантским часом. Я привел четыре случая, имевших место в начале пандемии, когда люди уже обращались в административные суды, чтобы задать вопрос, были ли ограничения приняты в соответствии с федеральным законодательством или конституцией провинции.

Тем временем суды приняли решение по ряду дополнительных дел. Ожидается, что еще больше дел будут переданы в суд. Однако некоторые из недавних решений заслуживают более внимательного рассмотрения, чтобы лучше понять, как конституционные требования оцениваются в свете ограничений. Поэтому я начну с краткого обзора судебной системы Германии, которая позволяет обжаловать решения исполнительной власти. Это необходимо для того, чтобы понять почему появилось множество различных судебных решений. Затем я перейду к обсуждению некоторых выдающихся судебных постановлений. В конце я попытаюсь оценить какое прецедентное право, связанное с COVID-19, появляется в Германии, и что это означает для легитимной борьбы с пандемией.

3 Смотри также Josef Joffe, “On Coronavirus, Beware the Totalitarian Temptation," The American Interest, March 17, 2020, www.the-american-interest.com/2020/03/17/oncoronavirus-beware-the-totalitarian-temptation. 


\section{Система административных судов в Федеративной Республике Германии}

Немецкая система оспаривания административных актов во многих отношениях уникальна по сравнению не только с системами непосредственных европейских соседей, но и в глобальном масштабе. Она гарантирует полный набор возможностей для лиц, нуждающихся в правовой защите. Большинство дел начинаются с административного решения властей (т. е. федеральных, провинциальных или муниципальных), которое пострадавший житель считает незаконным (например, лишение водительских прав, отказ в предоставления убежища, отказ в выдаче разрешения на строительство, поступление в государственные университеты, вопросы налогообложения и др.). Истца обычно информируют о его или ее праве опротестовать решение. Если учреждение придерживается своего первоначального исполнительного акта, истец имеет право потребовать правовой проверки в административном суде.

Первый уровень - это местный Verwaltungsgericht (Административный суд). На этом очень раннем этапе административный спор рассматривается исключительно на уровне провинции. Исключением могут быть случаи, когда заявитель оспаривает решение, принятое федеральным органом власти Германии (т.е. споры между федеральными министерствами и их федеральными государственными служащими по поводу повышения по службе или нарушения служебных обязанностей). Если суд первой инстанции согласен с первоначальным исполнительным актом, то пострадавший гражданин может подать апелляцию. Спор переходит на другой уровень в Oberverwaltungsgericht или, в зависимости от традиционного термина, используемого на земском уровне, Verwaltungsgerichtshof (Высший административный суд). Если истец сталкивается с другим отрицательным решением, он может потребовать пересмотра. Это означает, что истец покидает соответствующий земельный уровень и передает дело в так называемую Revisionsinstanz на высшем административном уровне Федеративной Республики, Bundesverwaltungsgericht. Формально дело на этом заканчивается. Однако гражданин также имеет право заявить, что последнее решение является нарушением его/ее основных прав. В таком случае окончательно вопрос рассмотрит Bundesverfassungsgericht (Конституционный суд) в Карлсруэ, но исключительно в аспекте нарушения основных прав, закрепленных в Основном законе Германии, Grundgesetz. Этот судебный орган отличается от Верховного суда США, у которого есть полномочия в реальности пересмотреть закон.

Что касается ограничений, связанных с коронавирусом, проблемы с ограничениями в связи с введением комендантского часа можно найти в двух основных процедурах. Во-первых, дело может быть возбуждено исключительно на основании наложения штрафа из-за нарушений, связанных 
c COVID-19 (например, на поставщика услуг питания, который проигнорировал запрет на прием гостей). Штраф является средством воздействия административного акта на истца. Поэтому он или она может подать апелляцию в орган на местном уровне, который выдал административный акт. Если агентство-эмитент не видит юридических или фактических обстоятельств, заставляющих его изменить свою позицию, дело будет передано в суд первой инстанции. С этого момента дело будет рассматриваться в соответствии с описанными выше процедурами до тех пор, пока гражданин не возьмет верх или не откажется от дальнейших процессов. Во-вторых, потенциальный податель апелляции может также оспаривать различные постановления о временном введении комендантского часа, принятые всеми 16 провинциями Германии.

Процесс юридического оспаривания постановлений министерств должен пройти через более высокий порог, чем процесс обжалования индивидуального административного акта. Причина в том, что эти указы носят коллективный характер. Они касаются определенной группы или всех жителей страны. В основном они абстрактны по характеру. Большинство земель Германии предоставляют возможность обжаловать постановления, ${ }^{4}$ однако заявитель должен доказать, что постановление затрагивает его или ее индивидуально. Немецкое законодательство не предусматривает неограниченную свободу подачи так называемых Popularklagen (общественных исков). Тем не менее, ограничения в связи с комендантским часом, введенные министерствами здравоохранения земель в середине марта, были сформулированы напрямую, были нацелены на профессиональные группы, общественные институты и на взаимодействие граждан друг с другом. В зависимости от структуры административной судебной системы провинции, рассмотрение соответствующей части постановления должно быть начато в высшем суде земельного уровня, таким образом минуя муниципальную стадию. Суд может объявит правонарушением спорную часть, но не постановление как таковое.

Как следствие, законодательному органу потребуется переформулировать рассматриваемый раздел в соответствии с решением суда. К этому примечанию можно добавить, что судебные решения и постановления не создают прецедентной практики в англосаксонской правовой традиции. Немецкие постановления исправляют имеющееся нарушение, создают прецедент для аналогичных дел и создают стандарты толкования.

Учитывая два основных варианта обращения за правовой защитой, на самом раннем этапе были заведены ряд дел, когда впервые были изданы общегерманские постановления о комендантском часе. В большинстве из них истцы искали временного правосудия. Эта Vorläufiger Rechtsschutz,

4 Смотри статью 120 Баварской конституции: «Каждый житель [...], который чувствует, что его конституционные права были нарушены административным органом, имеет право потребовать защиты в Баварском конституционном суде», www.bayern.landtag.de/fileadmin/scripts/get_file/Bavarian_Const_2003_BF.pdf. 
предварительная правовая защита, позволяет истцам пройти ускоренное судебное разбирательство. Затем суд принимает временное решение. Оно может быть изменено более поздним решением, когда суд найдет время для оценки дела по существу. Юридический пересмотр также возможен в тех случаях, когда исполнительный орган немедленно выполняет административный акт (например, роспуск собрания или демонстрации, нарушающие комендантский час). ${ }^{5}$ Такие дела заводятся с видом на последующую оценку. В случае принятия решения в пользу истца суд объявляет эту меру предпринятой незаконно. Одним из следствий этих решений является то, что они имеют рекомендательный характер для будущих исполнительных действий. Власти должны переосмыслить предполагаемый курс действий в сопоставимых случаях.

В следующем разделе я представлю несколько решений, принятых судами разных уровней. В их число входят решение высшего суда Германии, Федерального конституционного суда в Карлсруэ, а также конституционных судов на уровне провинции и высшего административного суда земли. Большинство этих судебных решений было принято в ускоренном порядке с целью добиться временного правосудия. Эта подборка показывает как дела рассматриваются разными судами в разных регионах Германии. Я также выбрал дела, в которых предполагалось множество нарушений основных прав.

\section{Федеральный конституционный суд / Свобода собраний}

Конституционный суд Германии постановил, что город Гиссен (расположенный недалеко от Франкфурта в земле Гессен) должен разрешить демонстрацию около 30 человек на центральной площади. ${ }^{6}$ В соответствии с процедурами, демонстранты сделали заявку о предполагаемом собрании в соответствующий офис городской администрации Гиссена. Демонстранты также представили схему, показывающую как участники могут поддерживать необходимое расстояние друг от друга и как можно транслировать выступления. Городские власти отклонили заявление на демонстрацию и сослались на первый абзац ранее введенного гессенского указа о временном комендантском часе. Немедленные апелляции в компетентный городской административный суд и Высший административный суд земли Гессен не увенчались успехом. Поэтому дело было передано в Конституционный суд, поскольку истцы утверждали, что запрещение демонстрации нарушает их право на свободу собраний (статья 8 Основного закона: все немцы имеют право собираться мирно и без оружия без предварительного уведомления

5 Volkmar Götz, Allgemeines Polizei- und Ordnungsrecht, 10th ed. (Göttingen: Vandenhoeck \& Ruprecht, 1991), p. 151 et seq.

6 Bundesverfassungsgericht, Beschluss vom 15. April 2020, 1 BvR 828/20; CM. Pressemitteilung Nr. 25/2020 vom 16. April 2020 Antrag auf Erlasss einer Einstweiligen Anordnung gegen Versammlungsverbot teilweise erfolgreich. 
или разрешения). Юрисконсульты города утверждали, что постановление о комендантском часе следует понимать как закон, регулирующий собрания на открытом воздухе. В пункте 2 статьи 8 Основного закона говорится, что право на собрания может быть ограничено законом или вследствие закона. Они интерпретировали указ о комендантском часе, согласно которому жители должны свести к абсолютному минимуму физические и социальные контакты с лицами, не являющимися членами их собственной семьи, что было бы невозможно во время демонстраций. Конституционный суд, однако, подчеркнул, что город по своему усмотрению принимает решение о демонстрации в соответствии с Законом о собраниях Германии (раздел 15 о запрещении, роспуске и правилах, пункт 1: Компетентный орган власти может запретить собрание или шествие, или потребовать, чтобы при организации выполнялись конкретные инструкции, если из-за обстоятельств, имевших место во время вынесения судебного запрета, общественная безопасность или порядок находятся под прямой угрозой в результате проведения собрания или шествия). Судьи критиковали мнение администрации Гиссена о том, что комендантский час может запретить любые демонстрации, как таковые, и что не было предпринято никаких попыток раскрыть обстоятельства дела. Суд установил, что указ Гессена не запрещал все демонстрации вообще.

Далее, суд в Карлсруэ подчеркнул, что свобода собраний является важным конституционным правом, которое необходимо учитывать. ${ }^{7}$ Конституционный суд обязал город Гиссен пересмотреть свое решение в свете этой интерпретации. Город так и сделал, и демонстрация состоялась. Несколько человек собралась организованно, чтобы сохранить необходимое физическое расстояние между демонстрантами.

\section{Конституционный суд земли Саар / Свобода личности}

Во временном судебном решении от 28 апреля 2020 года, которое обсуждалось в масштабах всей Германии, Конституционный суд Саара (довольно небольшого западного немецкого государства, граничащего с Францией и Люксембургом), в самом начале после введения комендантского часа произнес о запрете покидать дом. ${ }^{8}$ Истец оспорил постановление Саара о введении временного комендантского часа. Это постановление было составлено по образцу баварского указа. Постановление Саара также призывало жителей оставаться дома и ограничить контакты с людьми, не являющимися членами их собственной семьи. Постановление Саара также определяло те случаи, когда человеку разрешалось покинуть собственный дом. Это

7 Смотри также: Dieter Hesselberger, Das Grundgesetz, 12th ed. (Bonn: Bundeszentrale fuer politische Bildung, 2001), c. 127.

8 Verfassungsgerichtshof des Saarlandes, Beschluss vom 28. April 2020, Lv 7/20. 
было разрешено только по уважительным причинам. Постановление возлагает на человека обязанность предоставить веское объяснение того, почему он или она ушли из дома.

В данном случае истец утверждал, что соответствующие разделы ограничивали его личную свободу и что он имеет право находиться в публичном месте без обязанности указывать какие-либо конкретные причины. В своем решении Конституционный суд Саарбрюккена сначала подробно остановился на праве истца добиваться временного правосудия в высшем суде Саара. Он в основном одобрил процедуру, аргументируя это тем, что рассматриваемый правовой вопрос представляет «общий интерес» и что указ может нарушить многие основные права большого числа жителей. При проведении правовой оценки суд признал, что исполнительная власть несет ответственность за оценку степени угрозы жизни и здоровью своих граждан, создаваемой пандемией. Поэтому, суд в целом понимал, что право на свободу может быть ограничено в этих обстоятельствах. Затем он в равной степени подчеркнул, что влияние прав на свободу, прав первостепенной важности для либеральной демократии, требуют постоянного контроля со стороны судебной власти. С этого момента судьи придерживались мнения, что основания администрации для принятия решения о введении комендантского часа необходимо будет постоянно держать на контроле. Здесь именно суд коснулся самой сути спора о данных, собранных вирусологами, предлагающих жесткие меры социальной изоляции для предотвращения дальнейшего распространения COVID-19. Суд сравнил количество заражений с другими немецкими провинциями, граничащими с европейскими странами. Судьи связали эти более высокие показатели инфицирования с цифрами уровня инфицирования в своей провинции. Конституционный суд отверг предположение, что данные имеют значение для позиции, занятой правительством Саара. Суд пошел даже дальше и процитировал исследование ETH Zurich (Швейцарский федеральный технологический институт в Цюрихе) под названием «Оценка воздействия нефармацевтических интервенций на задокументированные случаи COVID-19: сравнительный анализ между разными странами ${ }^{9}{ }^{9}$ Согласно этому исследованию, ограничения, связанные с комендантским часом, имеют «лишь небольшую добавленную стоимость», и нужно также учитывать, что «изоляция также влечет за собой запрет на публичные мероприятия и собрания». Судьи следовали этой линии аргументов, когда искали баланс между намерением правительства сохранять здоровье населения и минимизировать смертность, и правом человека на свободу. Суд продолжил, применив данные к случаю тех, кто предлагает более жесткие ограничения, и к тем, кто выступает за

9 Nicolas Banholzera, Eva van Weenen, Bernhard Kratzwald, Arne Seeliger, Daniel Tschernutter, Pierluigi Bottrighi, Alberto Cenedese, Joan Puig Salles, Werner Vach, and Stefan Feuerriegel, "Impact of Non-pharmaceutical Interventions on Documented Cases of COVID-19: A Cross-country Analysis," medRxiv, April 21, 2020, https://doi.org/10.1101/2020.04.16.20062141. 
ослабление комендантского часа. Применяя указ администрации Саара к различным сценариям общественных собраний, суд в частности поинтересовался, почему членам семьи может быть разрешено присутствовать на похоронах умершего родственника в соответствии с постановлением о комендантском часе, в то время как людям запрещено собираться в общественных местах. Суд подчеркнул, что он не намерен действовать в качестве законодателя, но рекомендовал правительству изменить формулировку соответствующих разделов указа о комендантском часе. Рекомендации предусматривали, что гражданин должен быть освобожден от обязанности объяснять, почему он или она уходит из дома. В свете этого решения теперь каждый может покинуть свой дом, когда ему заблагорассудится. Правительство, наоборот, должно аргументировать любые будущие ограничения на основе убедительных доказательств.

\section{Высший административный суд Мюнхена / Недискриминация}

Очередное, активно обсуждаемое решение административного суда было принято в Баварии. ${ }^{10}$ В начале мая 2020 года правительство Мюнхена начало ослаблять ограничения и внесло поправки в соответствующие постановления, чтобы магазины с максимальной торговой площадью $800 \mathrm{~m}^{2}$ могли снова заработать. Истец - корпорация популярных торговых центров в Мюнхене, Берлине и Гамбурге - утверждал, что был нарушен принцип недискриминации согласно статье 118 Баварской конституции (Все равны перед законом. Законы обязательны для всех одинаково, и каждый пользуется защитой закона таким же образом). Консорциум торговых центров обратился за временной правовой защитой после того, как были объявлены изменения в указе. Процедура была направлена прямо в Высший административный суд Баварии. При оценке того, нарушает ли положение, разрешающее повторное открытие предприятий розничной торговли с максимальной площадью до $800 \mathrm{~m}^{2}$, принцип недискриминации, суд в целом заявил, что законодателям разрешено рассматривать разные случаи по-разному. Однако, дополнил суд, в случае, если правительство действительно желает применить такие разные критерии к разным сценариям, оно должно тщательно обосновать свои доводы. Высший административный суд Мюнхена не усмотрел какой-либо дискриминации в различных оценках риска заражения в пригородном магазине для инструментов или в торговом центре в центре города. Но он посчитал смягчение ограничений в пользу более крупных книжных или велосипедных магазинов как дискриминационное в связи с ограничением, которое фактически закрывало тор-

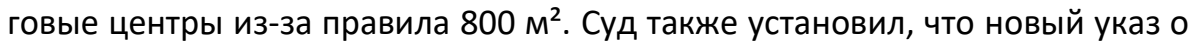

10 "Corona-Pandemie - Keine Aussetzung des Vollzugs der Bayerischen Infektionsschutzmaßnahmeverordnung," Beschluss vom 27.04.2020 - 20 NE 20.793 (Verwaltungsgerichtshof München, 2020), https://www.gesetze-bayern.de/Content/Pdf/Y-300-ZBECKRS-B-2020-N-6630?all=False. 
комендантском часе нарушает принцип соразмерности. Он подчеркнул серьезное воздействие ограничения на права собственников и не смог разде-

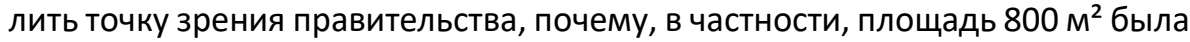
определена как порог. Как следствие, правительство Баварии было вынуждено разрешить открытие торговых центров.

\section{Конституционный суд Берлина / Свободное развитие личности}

Берлин - это не только столица Германии, это еще и земля (Land). Он похож на две другие земли (Länder) с небольшой территорией - ганзейские города Гамбург и Бремен. Эти три земли образуют вместе с 13 провинциями Flächenstaaten 16 государств Федеративной Республики. Поэтому, в Берлине действует Конституционный суд. Член коллегии адвокатов Берлина подал иск в Конституционный суд, где потребовал временной правовой защиты. ${ }^{11}$ Он утверждал, что введенные сенатом ограничения комендантского часа (исполнительная власть Берлина эквивалентна исполнительной власти правительств территориальных земель Германии) и соответствующий реестр штрафов сами по себе являются нарушением его конституционных прав и свобод. Он утверждал, что комендантский час не позволит ему участвовать в профессиональных собраниях, посещать библиотеки и покидать свой дом. В общем, он считал, что свобода развития его личности находится под угрозой (Freie Persönlichkeitsentfaltung ${ }^{12}$ ). Суд прекратил дело. Большинство судей посчитали, что заинтересованность Сената в поддержании работающей системы здравоохранения и его усилия по сглаживанию кривой роста числа инфицированных COVID-19 граждан имеют более важное значение. Они обрисовали ситуацию, в которой люди могут действовать без каких-либо правил, требующих физического дистанцирования. Суд вынес решение против адвоката, заявив, что он не смог обосновать, почему указ Сената окажет на него значительное влияние. Это решение также примечательно тем, что два конституционных судьи опубликовали особые мнения, что необычно для немецкой правовой традиции. Они особо раскритиковали указ и список штрафов в плане их ясности, точности (Bestimmtheit ${ }^{13}$ ), и отсутствие подробного объяснения того, почему конкретные ограничения оправдывают такое серьезное воздействие на основные права.

11 Verfassungsgerichtshof des Landes Berlin, "VerfGH Berlin: Erfolgloser Eilantrag eines Rechtsanwaltes im Zusammenhang mit der Covid19-Pandemie - Folgenabwägung Sondervotum," April 14, 2020, 50 A 20/20, www.gerichtsentscheidungen.berlinbrandenburg.de/jportal/?quelle=jlink\&docid=KVRE001092015\&psml=sammlung.psm I\&max=true\&bs=10.

12 Смотри Peter Schade, Grundgesetz mit Kommentierung (Regensburg: Walhalla Fachverlag, 2001), с. 23 и последующие.

13 Steffen Detterbeck, Allgemeiens Verwaltungsrecht (München: C.H.Beck, 2002), c. 64. 


\section{Итоги}

Упомянутые выше случаи являются лишь небольшой выборкой. Новые решения, а иногда и определения, принимаются ежедневно. Было бы легко продолжить рассмотрение многих других дел, которые продемонстрировали бы как административные и конституционные суды пытались сбалансировать защиты основных прав человека и потребности общественного здравоохранения. Можно спросить имеются ли какие-либо особенности административной юрисдикции Германии. Совершенно очевидно такие особенности существуют.

Рассматривая только результаты, можно увидеть, что истец не всегда побеждает. Например, административный суд Лейпцига вынес решение против отца, который хотел присутствовать при рождении его детей. Судьи решили, что заинтересованность больницы в поддержании безвирусного медицинского учреждения выше, чем желание отца увидеть рождение своих близнецов. Иногда суды соглашались с широким набором ограничительных инструментов, но сомневались в каком-нибудь их конкретном подмножестве.

Одна из особенностей заключается в том, что немецкая судебная система придерживается своей традиции концентрироваться на очень индивидуальных случаях и на оценке конкретики (Einzelfallbetrachtung). ${ }^{14}$ Как следствие, физические (или юридические) лица будут продолжать подавать иски. Неблагоприятные решения или постановления не обязательно означают, что суд не будет оценивать конкретный аспект иначе в другой процедуре.

Судьи признавали полезность введения ограничений, обеспечивающих физическое дистанцирование или обязанности носить защитное снаряжение, но они также признавали экономические или социальные последствия изоляции. В целом суды не стремились вступать в горячие общественные дебаты по трилемме защиты системы общественного здравоохранения, защиты гражданских прав и поддержания функционирующей экономики. При тщательном изучении решений можно сделать вывод, что судьи неоднократно требовали от правительств адекватного обоснования накладываемых ограничений. До сих пор упор делался на конкретный выбранный административный инструмент, который оспаривался. Судьи, принимавшие решение в пользу истца, критиковали то, что не были представлены надлежащие данные в соответствие с применением конкретной меры, ограничивающей права и свободы человека. Это привело к ключевому замечанию о том, что федеральные и государственные суды должны строго придерживаться принципа соразмерности. ${ }^{15}$ Ограничительная мера может быть законной только в том случае, если общественная цель ясна, если она необходима, если нет более мягкой меры и если поддержание общественной

14 Detterbeck, Allgemeiens Verwaltungsrecht, c. 131, 132.

15 Münchow, "COVID-19: How to Implement a Lockdown," c. 14-16. 
цели настолько приоритетно, что оправдывает интенсивность ограничения основного права личности.

Представляя решения административных судов, связанных с коронавирусом, в политическом контексте Германии в конце весны / начале лета 2020 года, необходимо признать, что судьи хорошо справились со своей функцией, обеспечивая систему сдержек и противовесов. После нескольких недель изоляции (которая была относительно мягкой по сравнению с некоторыми западными и южными странами-членами ЕС), обсуждение «за» и «против» ограничений приобрело гораздо более политический и эмоциональный характер, чем в начале весны. Тон изменился даже в политических лагерях. Некоторые политики даже не могли скрыть своего общественного беспокойства из-за некоторых судебных решений (что обычно является анафемой в немецкой политике). Тем временем в Берлине, Штутгарте, Мюнхене и других городах прошли демонстрации тысяч граждан, которые проигнорировали установленные правила физического дистанцирования и требовали «возвращения к нормальной» ситуации.

Уголовные суды Германии до сих пор избегают рассмотрения правовых вопросов, связанных с коронавирусом. Во время критической фазы в марте и апреле 2020 года государственным системам здравоохранения удалось удержать количество пациентов, которым требуется вентиляция легких, на низком уровне, пока они не смогут обновить свое оборудование для интенсивной терапии. Поэтому, ни в одном уголовном суде не было возбуждено дело для вынесения приговора по так называемой сортировке. Таким образом, ни один врач еще не был обвинен в принятии решения о приоритетности лечения пациентов на основе вероятности выздоровления с лечением или без него. Оценка этих сценариев в соответствии с уголовным кодексом и конституционными требованиями заслуживает отдельной статьи.

\section{Общая картина}

Решения административных судов до сих пор можно рассматривать как трезвые интервенции, которые не ставили под сомнение цель предотвращения дальнейшего распространения вируса, а были приняты для того, чтобы обуздать любые чрезмерно амбициозные меры правительства по поддержанию здоровья населения за счет индивидуальных свобод и прав. Можно даже добавить, что в судебных решениях учтена сама природа пандемии. Инфекция в промышленных центрах Германии выросла, что связано с глобализацией. Эпидемия COVID-19 вспыхнула в домах престарелых и вокруг них. Вирус распространился на горнолыжных курортах. В то же время, в меньших количествах он встречался на менее населенных берегах Балтийского моря. Таким образом, местные обстоятельства были учтены судами, которые требовали принятия пропорциональных и региональных мер. Важное значение имеют местонахождение бизнеса, близость к границе со страной с более высоким уровнем заражения, а также тщательные меры предо- 
сторожности при организации демонстрации. В постановлениях учитывались не только конкретные обстоятельства, но и интересы отдельных лиц в духе in dubio pro libertate.

Если посмотреть на это с точки зрения макроуровня, упомянутой в начале этой статьи, у правительства Германии никогда не было инструментов, позволяющих изолировать городскую территорию с 10 миллионами жителей. Основной закон 1949 года также не позволяет администрации Германии заставлять граждан загружать приложения для отслеживания. Излишне говорить, что критически настроенные исследователи, врачи, блогеры и журналисты не «исчезли» и не падали таинственным образом из окон. ${ }^{16}$ В отношение пандемии, федеральное правительство воздержалось от любой жесткой риторики, рассчитанной на запугивание его внешних противников. Оно противостояло попыткам продать операции по оказанию гуманитарной помощи мировой аудитории, добиваясь уважения и комплиментов. В отличие от российских или китайских мероприятий, когда прибывавшее медицинское оборудование сопровождалось взводом дружелюбных к режиму журналистов для создания позитивных образов и нарративов, лечение итальянских и французских пациентов в немецких больницах в основном не разглашалось. Администрация Берлина никак не отреагировала на кокетливые предложения Москвы в разгар кризиса. Вместо этого Саксония рассматривала возможность предложить койки российским пациентам, чтобы они могли лечиться от COVID-19 в немецких больницах. Немецкое антикризисное управление, похоже, было здравомыслящим. Система здравоохранения пережила вспышку болезни весной 2020 года на удивление хорошо, и в настоящее время дипломаты Германии ведут переговоры о финансовых мерах защиты от имени своих европейских партнеров. Параллельно с этим министерство обороны пытается изучить новые пути развития сотрудничества между ЕС и НАТО для обеспечения военной мобильности в будущем, способы противодействия совместным гибридным угрозам и аналогичным проблемам. Спокойный подход, при котором суды уравновешивали инструменты борьбы с коронавирусом и соображения верховенства закона, способствовал созданию необходимой мозаики общих достижений. Короче говоря, можно также иметь в виду этот основанный на верховенстве закона подход, свободу доступа к средствам правовой защиты и здравую судебную систему, когда нужно противодействовать нарративам авторитарных режимов на Востоке, которые утверждают, что лучше служат обществу в борьбе с COVID-19.

16 "Corona-Zensur in China: Die verschwundenen Blogger von Wuhan," Tagesschau.de, May 23, 2020, https://www.tagesschau.de/ausland/china-blogger-101.html; Смотри также: "Mysteriöse Todesumstände: Zwei russische Ärzte nach Systemkritik durch Fenstersturz gestorben," t-online.de, May 5, 2020, www.t-online.de/nachrichten/ ausland/id_87819616/corona-in-russland-zwei-aerzte-nach-kritik-durch-

fenstersturz-gestorben.html. 


\section{Отказ от ответственности}

Выраженные здесь взгляды являются исключительно взглядами автора и не отражают точку зрения Консорциума оборонных академий и институтов изучения безопасности ПрМ, участвующих организаций или редакторов Консорциума.

Издание Connections: The Quarterly Journal, том 19, 2020 осуществляется при поддержке правительства Соединенных Штатов.

\section{Об авторе}

Д-р Себастьян фон Мюнхов - преподаватель Европейского центра исследований безопасности им. Джорджа К. Маршалла в Гармиш-Партенкирхене, Бавария. Он изучал право в Свободном университете Берлина, Университете Лозанны и Университете Кристиана Альбрехта в Киле. В 2000 году он получил докторскую степень по международным отношениям в Венском университете. С 1998 по 2002 год он работал в полевых миссиях Организации по безопасности и сотрудничеству в Европе в Боснии и Герцеговине, а также в Косово. Он также работал в Миссии Европейского Союза по оказанию помощи полиции в Тиране. В период с 2003 по 2005 год доктор фон Мюнхов руководил различными инициативами, связанными с домашними проблемами и правосудием, в Брюссельском офисе Специального координатора Пакта стабильности для Юго-Восточной Европы. В 2006 году доктор фон Мюнхов вернулся в Германию и несколько лет проработал в администрации Федерального канцлера в Берлине, прежде чем присоединиться к Центру Маршалла в 2012 году. В области его компетентности входят парламентский надзор, верховенство закона и строительство потенциала в ЮгоВосточной Европе. С 2019 года д-р Себастьян фон Мюнхов является директором Восточного семинара по европейской безопасности. 